\title{
Reevaluation of the proposed autocrine proliferative function of prolactin in breast cancer
}

\author{
Louise Maymann Nitze $\cdot$ Elisabeth Douglas Galsgaard $\cdot$ Nanni Din • \\ Vibe Luja Lund · Birgitte Bruun Rasmussen - Martin Werner Berchtold • \\ Leif Christensen $\cdot$ Svetlana Panina
}

Received: 23 July 2013/Accepted: 8 October 2013/Published online: 22 October 2013

(C) The Author(s) 2013. This article is published with open access at Springerlink.com

\begin{abstract}
The pituitary hormone prolactin (PRL) has been implicated in tumourigenesis. Expression of PRL and its receptor (PRLR) was reported in human breast epithelium and breast cancer cells. It was suggested that PRL may act as an autocrine/paracrine growth factor. Here, we addressed the role of locally synthesised PRL in breast cancer. We analysed the expression of PRL in human breast cancer tumours using $\mathrm{qPCR}$ analysis and in situ hybridization (ISH). PRL mRNA expression was very low or undetectable in the majority of samples in three cDNA arrays representing samples from 144 breast cancer patients and in 13 of 14 breast cancer cell lines when analysed by qPCR. In accordance, PRL expression did not
\end{abstract}

Electronic supplementary material The online version of this article (doi:10.1007/s10549-013-2731-7) contains supplementary material, which is available to authorized users.

L. M. Nitze · E. D. Galsgaard · N. Din .

V. L. Lund · L. Christensen - S. Panina

Biopharmaceutical Research Unit, Novo Nordisk A/S,

Bagsvaerd, Denmark

L. M. Nitze - M. W. Berchtold ( $\square)$

Department of Biology, University of Copenhagen, Ole Maaloes

Vej 5, 2200 Copenhagen, Denmark

e-mail: mabe@bio.ku.dk

V. L. Lund

Department of Anatomy and Cell Biology, University of

Copenhagen, Copenhagen, Denmark

Present Address:

V. L. Lund

DAKO Denmark A/S, Glostrup, Denmark

B. B. Rasmussen

Department of Pathology, Herlev University Hospital, Herlev, Denmark reach detectable levels in any of the 19 human breast carcinomas or 5 cell lines, which were analysed using a validated ISH protocol. Two T47D-derived breast cancer cell lines were stably transfected with PRL-expressing constructs. Conditioned medium from the T47D/PRL clones promoted proliferation of lactogen-dependent $\mathrm{Nb} 2$ cells and control T47D cells. Surprisingly, the PRL-producing clones themselves displayed a lower proliferation rate as compared to the control cells. Their PRLR protein level was reduced and the cells were no longer responsive to exogenous recombinant PRL. Taken together, these data strongly indicate that autocrine PRL signalling is unlikely to be a general mechanism promoting tumour growth in breast cancer patients.

Keywords Autocrine prolactin - Breast cancer . Ectopic expression - In situ hybridization - qPCR

\section{Introduction}

The polypeptide hormone prolactin (PRL) is synthesised by lactotrophs of the anterior pituitary and acts as a classical endocrine hormone. PRL is important for proliferation and differentiation of the breast epithelium as well as for stimulation of lactation after delivery [1]. PRL mediates its effects through the PRL receptor (PRLR). It binds via site 1 to one receptor chain forming a 1:1 ligand-receptor complex. Subsequent binding to a second identical receptor molecule via binding site 2 results in the active 1:2 ligandreceptor complex. Upon dimerization, PRLR and associated JAKs become phosphorylated and activate multiple signalling pathways including STAT5, STAT3, ERK1/2 and AKT. PRL binding also induces PRLR ubiquitination, internalisation and degradation [2]. 
A number of studies have pointed towards a role of PRL in breast cancer development. Increased plasma concentration of PRL observed in breast cancer patients positively correlated with poor prognosis and the occurrence of metastatic breast cancer [3]. A growth-promoting effect of PRL on human breast cancer cells in vitro has been demonstrated by several laboratories including ours [4-6]. In addition, PRL was shown to play a role in development of murine mammary tumours [7-9]. It has been reported that in humans PRL can be produced at extra pituitary sites [10, 11]. Although at markedly lower levels compared to pituitary, PRL mRNA expression was clearly demonstrated in placental decidualized endometrium specimens by Gellersen et al. [12]. Moreover, PRL mRNA was also detected in normal breast epithelium and breast cancer tissues [13-18] and since PRLR was also found to be expressed in the breast gland and breast cancer cells, it was hypothesised that PRL can promote breast cancer progression in an autocrine/paracrine manner.

To mimic the proposed autocrine/paracrine loop in human, transgenic murine models with tissue-specific PRL expression were used. Local overexpression of PRL was found to promote breast cancer development in virgin transgenic animals [8, 9, 19]. In contrast, no carcinomas were found in PRL transgenic mice with differentiated mammary glands, where PRL expression was controlled by the milk whey acidic protein promotor [20]. Overexpression of PRL was also found to stimulate cell growth of the transfected human breast cancer cell lines, MCF-7 and MDA-MB435 [21, 22]. However, to date, it still remains unclear whether locally produced PRL contributes to human breast cancer progression.

In the present study, expression of PRL in breast cancer tissues and breast cancer cell lines as well as the potential role of local PRL in stimulation of cancer cell proliferation has been addressed. We show based on the analysis of mRNA expression in human breast cancer samples and in vitro studies with transfected breast cancer cell lines that locally synthesised PRL is unlikely to be a general mechanism promoting breast cancer progression.

\section{Materials and methods}

Breast cancer cell cultures and hormones

Human breast cancer cell lines MDA-MB361, AU565, BT20, BT474, BT549, MDA-MB157, MCF-7, MDAMB175 VII, MDA-MB231, MDA-MB468, SK-BR-3, ZR75-1 and T47D were purchased from ATCC (Manassas, VA), the T47D Tet-On cell line was from Clontech (Mountain View, CA), MFM 233 was purchased from ECACC (Salisbury, UK). Cells were routinely cultured in
DMEM medium supplemented with $10 \%$ FCS, 2 mM glutamax, $4.5 \mathrm{~g} / 1$ glucose (Invitrogen, San Diego, CA) and 100U penicillin/streptomycin (Invitrogen, San Diego, CA). In case of T47D, cell culture medium was supplemented with $0.01 \mathrm{U} / \mathrm{ml}$ human insulin (Novo Nordisk A/S, Denmark). For T47D Tet-On derived cells $10 \%$ FCS was replaced with $10 \%$ Tet System Approved FCS (Clontech, Mountain View, CA). In order to study the effects of ectopic and exogenous PRL, cells were cultured in phenol red-free DMEM supplemented with $10 \%$ charcoal/dextran stripped FCS (HyClone, Logan, UT), 2 mM glutamax, 4.5 g/l glucose, $100 \mathrm{U}$ penicillin and streptomycin (Invitrogen, San Diego, CA) (referred as $10 \% \mathrm{CSS}$ medium). All cells were propagated in $5 \% \mathrm{CO}_{2}$ humidified atmosphere at $37{ }^{\circ} \mathrm{C}$. Human recombinant PRL (rPRL) was expressed in Escherichia coli and purified as previously described [23]. 17-estradiol (E2) was purchased from Sigma-Aldrich (St.Louis, MO).

Detection of PRL mRNA in breast cancer tissue and breast cancer cell lines by qPCR analysis

Breast Cancer cDNA Arrays I, II and IV were obtained from Origene (Origene cat\# BCRT301, BCRT302 and BCRT303); according to supplier infiormation, each array contained cDNA samples synthesised from high quality total RNAs of pathologist-verified tissues, normalised and validated with ACTB ( $\beta$-actin) in two sequential qPCR analyses; arrays were provided with clinical information and quality control data, but absolute amount of cDNA/ well was not disclosed. BCRT301 contained 48 samples covering 7 stage 0,10 stage I, 13 stage IIA, 7 stage IIB, 8 stage IIIA and 3 stage IIIC breast cancers; BCRT302-48 samples covering 5 stage 0,11 Stage I, 8 IIA, 6 IIB, 8 IIIA, 2 IIIB, 4 IIIC, 4 IV breast cancers; BCRT304-48 samples covering 4 stage 0,2 stage I, 15 stage IIA, 9 stage IIB, 7 stage IIIA, 4 stage IIIB, 6 stage IIIC and 1 stage IV breast cancers. Two BCRT302 plates were used with undiluted samples for qPCR in a PRL-specific assay; another plate was divided in 4 equal aliquots and used for control qPCR analysis for PRLR (PRL receptor), PLAU, PLAUR (encoding uPA receptor) and ACTB. From each of BCRT301 and 304, two undiluted plates were used for PRL qPCR and one undiluted plate for ACTB. In order to increase the amounts of PRL and control cDNA in the Origene plates, one plate from BCRT301 was used for multiplex pre-amplification. Pre-amplification was performed using the TaqMan PreAmp Kit PN4384267 (Applied Biosystems) with a combination of the ABI assays for PRL and ACTB; cDNA samples were dissolved in $50 \mu \mathrm{l}$ assay mix and split into two equal aliquots which were both subjected to 14 cycles amplification as recommended by the kit manual, except that the final amplified samples were diluted only 5 times instead of 20 times. 
Breast cancer cell lines grown under standard conditions were used for isolation of total RNA, using TRIZOL. cDNA was prepared from $1 \mu \mathrm{g}$ of total RNA from each of the preparations using random primers and Superscript II Reverse Transcription reagents (Invitrogen A/S San Diego, CA) according to the manufacturer's instructions. Placental RNA (Clontech cat\# 636527) was used for cDNA synthesis as described for the cell line RNAs. For qPCR we used a cDNA amount corresponding to $40 \mathrm{ng}$ total RNA pr. reaction. Primers and FAM-labelled-probes for PRL and control genes were ordered as Assays-on-Demand from Applied Biosystems. Assay order numbers for these genes were: PRL Hs00168730_m1 (this assay is recommended by ABI to give best coverage of all PRL splice variants); PRLR Hs00168739_m1; PLAU Hs01547050_m1; PLAUR-1 Hs00182181_m1 and ACTB Hs99999903_m1.

Quantitative PCR (50 cycles) was performed on each of the cDNA samples with TaqMan PCR core reagents (Applied Biosystems), using the ABI PRISM ${ }^{\circledR}$ 7900HT Sequence Detection System. Data were analysed using ABI Prism SDS 2.2 software (Applied Biosystems); expression levels for each mRNA were estimated from the $\mathrm{Ct}$ values; for the breast cancer samples of BCRT302, Ct values for control genes have been corrected so as to reflect the values of undiluted samples. According to Applied Biosystems, $\mathrm{Ct}$ values of $\sim 40$ reflect the limit of detection, and values close to or above this limit are usually not reliable (referred as 'undetermined' further in the text).

Clinical tissue samples and cell lines for histology

\section{Breast cancer samples}

Formalin-fixed and paraffin-embedded (FFPE) human breast cancer carcinoma tissue samples from 19 patients were obtained from the biobank at Nordsjaellands Hospital, Hilleroed. The age of the patients was in the range 42-86 years with a median of 57 years. 15 patients had ductal carcinomas and four had lobular carcinomas. These carcinomas were classified as malignancy grade I $(n=1)$, II $(n=6)$ and III $(n=8)$. The grade was not reported for four of the tumours. 11 patients had lymph node metastases. Most of the tumours (14/19) expressed the estrogen receptor, and a subset of these (11/14) also expressed the progesterone receptor (Supplementary Table $2 \mathrm{~S}$ ).

\section{Positive control tissues and cell lines}

Human pituitary gland (FFPE) was obtained as tissue blocks (cat. no. 24070250), and as cut sections from Cambridge Bioscience Ltd., Cambridge, UK and from Pantomics, respectively. Human placenta (FFPE) was collected at Odense University and kindly provided by Dr.
Tornehave. Human breast cancer-derived cell lines (MDAMB361, AU565, BT20, BT474, BT549, MDA-MB157, MCF-7, MDA-MB175 VII, MDA-MB231, MDA-MB468, SK-BR-3，ZR-75-1，MFM223), T47D/PRL clones and control T47D cell lines $\left(5-10 \times 10^{6}\right.$ cells of each) were fixed in paraformaldehyde and embedded in small agar cylinders for processing and subsequent paraffin-embedding. All breast cancer and control tissue samples were collected with informed concent. Moreover, collection of tissues as well as conduction of the present study was approved by the local ethical committees.

\section{Generation of S35-labelled PRL cRNA probes}

A 507 bp PRL cDNA fragment (nucleotides 210-716 according to Genebank \# BC088370) was amplified from the pET32-PRL plasmid [23] by PCR using forward and reverse primers $5^{\prime}$ cccactacatccataacctctc and $5^{\prime}$ ggatgat tcggcacttcag, respectively. The PCR fragment was cloned into PCR-Script Amp SK (+) cloning vector. The PRL sequence was verified (service provided by MWG-Biotech, Germany).

As a control for the specificity of the hybridization of the PRL cRNA probe, two additional PRL probes were designed. They were shorter (196 and $222 \mathrm{bp}$ ) and represented two nonoverlapping regions of the PRL cDNA corresponding to nucleotides 210-405 and 495-716, respectively. The following forward and reverse primer sets were used to generate the two DNA fragments: $5^{\prime}$ cccactacatccataacctctc $+5^{\prime}$ caggatcgcaatatgctgac, and $5^{\prime}$ agcaaaccaaacggcttc $+5^{\prime}$ ggatgattc ggcacttcag, respectively.

To validate the suitability of the breast cancer samples for the ISH application, hybridization with a cRNA probe for the cancer marker gene PLAU-1, encoding urokinase plasminogen activator (uPA), was used. This probe represents a $513 \mathrm{bp}$ fragment of the open reading frame of the PLAU gene (corresponding to bp 691-1,024 in EMBO database AQC \#KO3226). It has previously been used to detect the PLAU gene expression in human breast cancer by ISH [24]. ${ }^{35} \mathrm{~S}-\mathrm{UTP}$ radiolabelled sense and antisense cRNA probes were transcribed from linearized plasmids using T3 or T7 polymerases.

In situ hybridization (ISH)

Paraffin-embedded tissue sections $(4 \mu \mathrm{m})$ were deparaffinised, rehydrated and pre-treated with proteinase $\mathrm{K}(5 \mu \mathrm{g} /$ $\mathrm{ml}$ ) at $37{ }^{\circ} \mathrm{C}$ for $5 \mathrm{~min}$ followed by post-fixation in $4 \%$ paraformaldehyde for $5 \mathrm{~min}$. After acetylation and dehydration, denatured ${ }^{35} \mathrm{~S}$-UTP labelled anti-sense or sense cRNA probes $(500,000 \mathrm{cpm}$ per $\mu$ hybridization solution: $1 \times$ SALTS with $50 \%$ formamide, $12.5 \%$ dextran sulphate, $1 \mu \mathrm{g} / \mathrm{ml}$ tRNA and $10 \mathrm{mM}$ DTT) were added. The 
tissue sections were incubated overnight with a probe at $47{ }^{\circ} \mathrm{C}$ in humidified atmosphere and hereafter washed in $1 \mathrm{x}$ SALTS with $50 \%$ formamide and $10 \mathrm{mM}$ DTT two times for $1 \mathrm{~h}$ at 62 and $67{ }^{\circ} \mathrm{C}$, respectively. The sections were treated with RNase A $(20 \mu \mathrm{g} / \mathrm{ml})$ for $30 \mathrm{~min}$ at $37{ }^{\circ} \mathrm{C}$ to further remove excess probe followed by additional washing for $30 \mathrm{~min}$ in $0.1 \times \mathrm{SSC}$ with $1 \mathrm{mM}$ DTT at room temperature (RT). Sections were dehydrated, air dried and dipped in auto-radiographic emulsion (Ilford K5). Slides with T47D/PRL clones, control cell lines and anterior pituitary tissue were developed after 1-2 weeks of exposure, whereas slides with placenta, breast carcinoma tissue and breast cancer cell lines were developed after 6-8 weeks of exposure. After development, slides were counterstained with Mayer's haematoxylin and eosin and then examined and photographed under both dark- and bright-field illumination. Positive hybridization with antisense probes was defined as clusters of silver grains observed over cells at densities higher than in sections hybridized with sense probe.

\section{PRL expression vectors}

Full-length human PRL cDNA was amplified using an expression plasmid previously described [23] as template with the following set of primers: $5^{\prime}$-ggttgctagctcacgaacatgaacatcaaagga and $5^{\prime}$-gtttggatccttagcagttgttgttgtggatgatt harbouring NheI and BamHI sites, respectively (underlined) to facilitate cloning to the corresponding sites of the pIRESneo2 expression vector (Clontech, Mountain View, CA). For cloning into the pTRE2hyg vector (Invitrogen, San Diego, CA), PRL cDNA was amplified using the following set of primers: $5^{\prime}$-ggttggatcctcacgaacatgaacatcaaagga and $5^{\prime}$ gtttgtcgacttagcagttgttgttgtggatgatt harbouring BamHI and SalI sites, respectively (underlined) to facilitate cloning to the corresponding sites of the vector. All constructs have been sequences. Transfection of T47D and T47D Tet-On cells was performed using Nucleofector (Amaxa Biosystems). T47D cells were transfected with $2 \mu \mathrm{g}$ of pIRESneo2hPRL (referred as T47D/pIRES-PRL); T47D Tet-On cells were transfected with pTRE2hyg-hPRL (referred as T47D/ pTRE-PRL). Stable transfectants were selected using geneticin $(500 \mu \mathrm{g} / \mathrm{ml})$ and hygromycin $(200 \mu \mathrm{g} / \mathrm{ml})$ for PRLtransfected T47D and T47D Tet-On, respectively. Parental T47D and mock (empty vector) transfected T47D Tet-On drug resistant pool were used as controls.

\section{Western blotting}

Western blot analysis was carried out as previously described [25]. For intracellular signalling studies, cells were rinsed with ice-cold PBS and snap frozen in liquid nitrogen prior to lysis in RIPA buffer. The following primary antibodies were used: anti-PRL rabbit polyclonal serum from AbCam (Cambridge, UK), anti-PRLR (clone 1A2B1) from Zymed (Invitrogen, San Diego, CA), anti- $\beta$ actin from AbCam (Cambridge, UK), anti-ERK1/2, antiCyclin D1 and anti-Bcl-2 from Cell Signalling Technologies (Danvers, MA), and anti-pERK1/2 ('anti-active MAPK') from Promega (Fitchburg, WI). Secondary HRPconjugated goat anti-mouse and swine anti-rabbit antibodies were purchased from Dako (Glostrup, Denmark). Image acquisition was performed using an LAS-3000 image reader (Fujifilm, Japan); the signal intensity was quantified using an Image Gauge V4 software.

Analysis of cell proliferation

Cell proliferation was estimated by measuring DNA synthesis using ${ }^{3} \mathrm{H}$-thymidine incorporation as previously described [6]. In brief, cells were incubated for $4 \frac{1}{2} \mathrm{hrs}$ with $0.5 \mu \mathrm{Ci}{ }^{3} \mathrm{H}$-thymidine with a specific activity $59.0 \mathrm{Ci} /$ mmol (GE Healthcare, UK), detached by trypsin and harvested using a 96-well cell harvester (TOMTEC, Hamden CT). ${ }^{3} \mathrm{H}$-thymidine incorporation was measured by liquid scintillation counting using a TopCount NXT (Perkin Elmer, Wellesley MA). Each treatment was performed in four to six replicates.

\section{Detection of secreted PRL}

T47D and T47D/PRL cells were grown until 50-80\% confluence in $10 \%$ FCS supplemented medium. To remove bovine PRL from the FCS medium, cells were washed twice in DMEM prior to $24 \mathrm{~h}$ of starvation in serum-free DMEM medium. Conditioned medium was collected (on ice) and the PRL content was analysed as described below. Cells were trypsinised and counted using a Nucleocounter (Chemometec).

The level of secreted PRL protein was measured using an ELISA kit (Duoset Human Prolactin, R\&D Systems, Abingdon, UK) according to the manufacturer's protocol. The PRL standards $(15.625-1,000 \mathrm{pg} / \mathrm{ml})$ and the conditioned medium (undiluted and $5 \times, 10 \times, 50 \times$ or $100 \times$ diluted) were analysed in duplicates and triplicates, respectively.

The level of biologically active PRL in the conditioned medium was measured using an $\mathrm{Nb} 2$ proliferation assay. The $\mathrm{Nb} 2$ rat $\mathrm{T}$ cell lymphoma cell line (purchased from ATCC) was routinely cultured in RPMI 1640 medium supplemented with $10 \%$ FCS, $10 \%$ horse serum, $1 \%$ non-essential amino acids, $2 \mathrm{mM}$ glutamax, $100 \mu \mathrm{M}$ 2-mercaptoethanol, $100 \mathrm{U}$ penicillin and streptomycin (Invitrogen, San Diego, CA). To remove PRL from the medium and to arrest growth of the cells prior to the assay, $\mathrm{Nb} 2$ cells were starved for $24 \mathrm{~h}$ in phenol red-free RPMI 
1640 medium supplemented with $1 \%$ horse serum, $1 \%$ non-essential amino acids, $2 \mathrm{mM}$ glutamax, $100 \mu \mathrm{M}$ 2-mercaptoethanol, $100 \mathrm{U}$ penicillin and streptomycin (Invitrogen, San Diego, CA) (starvation medium). $2 \times 10^{4}$ cells were seeded per well in a 96-well multi-dish. Human rPRL standards (Sigma, conc. 0.01-1,000 pM) and conditioned medium (undiluted and $10 \times$ or $100 \times$ diluted in starvation medium) were added in duplicates and cells were propagated for three days at $37{ }^{\circ} \mathrm{C}$ in a $5 \% \mathrm{CO}_{2}$ humidified incubator. $\mathrm{Nb} 2$ cell proliferation was indirectly estimated by measuring the metabolic activity of viable $\mathrm{Nb} 2$ cells using AlamarBlue (BioSource, Nivelles, Belgium). Cells were incubated with $0.04 \%$ AlamarBlue for $4 \mathrm{~h}\left(37{ }^{\circ} \mathrm{C}, 5 \% \mathrm{CO}_{2}\right)$. As a negative control, AlamarBlue was added to medium without cells. Absorbance of AlamarBlue was measured in a Wallac Victor plate reader using a fluorescent excitation wavelength of $544 \mathrm{~nm}$ and fluorescence emission at $590 \mathrm{~nm}$. The level of biologically active PRL in the conditioned medium was calculated based on the human rPRL standard curve after correction for background values of negative control samples.

\section{Co-culture of T47D and T47D/PRL clones}

T47D Tet-On cells were seeded at a density of $6 \times 10^{4}$ cells/well in a 24-well Falcon companion dish (BD BioCoat, BD Biosciences, San Diego, CA) in $10 \% \mathrm{CSS}$ medium. After one day, $0.4 \mu \mathrm{m}$ cell culture inserts (BD Falcon, BD Biosciences, San Diego, CA) were placed on top of each well and cells were seeded in the inserts with a density of approximately $80 \%\left(7 \times 10^{4}\right.$ T47D Tet-On cells or $9 \times 10^{4} \mathrm{~T} 47 \mathrm{D} / \mathrm{pTRE}-\mathrm{PRL} \mathrm{Cl} .4$ cells). Cells were cultured for three days in $10 \%$ CSS medium without removal of the medium to allow accumulation of PRL secreted by the T47D/PRL clones. The inserts were discarded and the PRL concentration in the medium was measured by ELISA as described above. Proliferation of cells was measured as described above.

\section{Cell cycle analysis}

Cells were cultured for three days in $10 \%$ FCS medium; each treatment was performed in triplicates. To include all cells, attached cells were harvested by EDTA/trypsin treatment and loose/suspension cells were collected from the medium. Cells were spun down, resuspended in PBS with $1 \%$ FCS and passed through a $45 \mu \mathrm{m}$ cell strainer to obtain a single cell suspension. DNA content was analysed by staining of permeabilised cells with propidium iodide. In brief, $1 \times 10^{5}$ cells were rinsed with ice-cold PBS with $1 \%$ FCS, fixed in ice-cold $70 \% \mathrm{EtOH}$ over night at $-20{ }^{\circ} \mathrm{C}$ and treated with a mixture of $25 \mu \mathrm{g} / \mathrm{ml}$ RNase and $50 \mu \mathrm{g} / \mathrm{ml}$ propidum iodide (BD Pharmingen, San Diego,
CA) for at least 20 min at RT (kept dark). The cells were analysed using a BD FACSArray ${ }^{\mathrm{TM}}$ flow cytometer. The cell cycle phase distribution was analysed using ModFit $\mathrm{LT}^{\mathrm{TM}}$ (Verity Software House) after exclusion of debris and doublets by manual gating.

Flow cytometry analysis of PRLR expression

Cells were detached using Versene solution and counted using a Nucleocounter. $1 \times 10^{5}$ cells were transferred to a U-bottom 96-well dish (Falcon, BD). Unspecific binding was blocked using PBS with $2 \%$ FCS $\left(30 \mathrm{~min}\right.$ at $\left.37{ }^{\circ} \mathrm{C}\right)$. Cells were stained with $1 \mu \mathrm{g} / \mathrm{ml}$ anti-PRLR mAb (Clone 250448; R\&D Systems) for $45 \mathrm{~min}$ at $37{ }^{\circ} \mathrm{C}$ or with mouse IgG1 isotype control (BD Pharmingen, San Diego, CA). Cells were rinsed once with cold PBS/0.5\% BSA and incubated with APC-conjugated anti-mouse IgG (Jackson ImmunoResearch, Suffolk, UK) for $30 \mathrm{~min}$ at $4{ }^{\circ} \mathrm{C}$. Cells were rinsed four times with cold PBS/0.5\%BSA and analysed by flow cytometry using BD FACSArray (BD Bioscience, San Diego CA).

\section{Results}

PRL mRNA expression in human breast carcinomas and cell lines analysed by qPCR

First, we validated the PRL and control qPCR assays on placental RNA. Under the conditions used, placenta showed a deltaCt value for PRL versus $\beta$-actin (ACTB) of 3.2 (Table 1), i.e. the PRL mRNA level was 9.2-fold lower than the ACTB mRNA level. Next, we examined 3 different commercial breast cancer cDNA arrays containing totally 144 samples (Table 1). Again, we used the deltaCt value for PRL vs ACTB as measure for PRL levels. We showed that ACTB Ct levels varied slightly between individual samples and markedly among the three arrays, demonstrating that Array I had a higher ACTB content followed by Array II and Array IV. PRL Ct values were generally high and many samples did not give rise to a $\mathrm{Ct}$ value at all $(\mathrm{Ct}>41)$, i.e. PRL was undetectable. The number of samples with undetected PRL mRNA was 16, 27 and 32 on arrays I, II and IV, respectively, reflecting the influence of cDNA template amount on the sensitivity of qPCR analysis. Using a PRL Ct value of $>41$ for these 75 samples, we could calculate deltaCT values vs ACTB demonstrating PRL levels that were at least 20.000-fold lower than in placenta in 28 of the samples and at least 100-2,000-fold lower than placenta in 47 samples. In the samples giving a PRL Ct value only one (sample\#34 on Array IV) had a value, which is close to the PRL level found in placenta, indicating a relatively high PRL level. 8 samples had medium PRL mRNA levels (8-32-fold 
Table 1 PRL qPCR analysis of Breast Cancer samples and placenta

\begin{tabular}{|c|c|c|c|c|c|c|c|c|}
\hline \multirow[t]{4}{*}{ Placenta } & \multirow{2}{*}{\multicolumn{3}{|c|}{$\frac{\mathrm{PRL}}{\mathrm{Ct}}$}} & \multirow{2}{*}{\multicolumn{2}{|c|}{$\frac{\text { PRL vs ACTB }}{\text { deltaCt }}$}} & \multicolumn{3}{|l|}{ ACTB } \\
\hline & & & & & & $\mathrm{Ct}$ & & \\
\hline & \multicolumn{3}{|l|}{27.2} & \multicolumn{2}{|l|}{3.2} & \multicolumn{3}{|l|}{24} \\
\hline & $\begin{array}{l}\text { No of } \\
\text { undetermined } \\
\text { samples }\end{array}$ & $\begin{array}{l}\mathrm{Ct} \\
\text { average }\end{array}$ & $\begin{array}{l}\text { Ct range } \\
\text { (PRL nd) }\end{array}$ & $\begin{array}{l}\text { deltaCt } \\
\text { average }\end{array}$ & $\begin{array}{l}\text { deltaCt ra } \\
\text { nge (PRL nd) }\end{array}$ & $\begin{array}{l}\text { No of } \\
\text { undetermined } \\
\text { samples }\end{array}$ & $\begin{array}{l}\text { Ct average all } \\
\text { (PRL nd) }\end{array}$ & $\begin{array}{l}\text { Ct range all } \\
\text { (PRL nd) }\end{array}$ \\
\hline $\begin{array}{l}\text { Breast cancer } \\
\text { cDNA array I }\end{array}$ & $16 / 48$ & $39 \pm 1.2$ & $\begin{array}{c}36.3-41.3 \\
(>41)\end{array}$ & $13.4 \pm 1.9$ & $\begin{array}{l}6.3-16.2 \\
\quad(>15-16.7)\end{array}$ & 0 & $\begin{array}{l}25.1 \pm 1.2 \\
\quad(25 \pm 0,6)\end{array}$ & $23.7-32(24.3-26)$ \\
\hline $\begin{array}{l}\text { Breast cancer } \\
\text { cDNA array II }\end{array}$ & $27 / 48$ & $39 \pm 1.1$ & $\begin{array}{c}36.8-40.9 \\
(>41)\end{array}$ & $12 \pm 1.5$ & $\begin{array}{l}7.3-14.1 \\
\quad(>12.1-15)\end{array}$ & 0 & $\begin{array}{l}27.4 \pm 0.7 \\
\quad(27.4 \pm 0.7)\end{array}$ & $26.0-29.5(26-28.9)$ \\
\hline $\begin{array}{l}\text { Breast cancer } \\
\text { cDNA array } \\
\text { IV }\end{array}$ & $32 / 48$ & $39 \pm 1.8$ & $\begin{array}{c}35.3-41.4 \\
(>41)\end{array}$ & $9 \pm 2.7$ & $\begin{array}{l}3.8-13.6 \\
\quad(>7.1-14.7)\end{array}$ & 0 & $\begin{array}{l}28.6 \pm 1.6 \\
\quad(28.3 \pm 1.5)\end{array}$ & $26.5-33.9(26.3-33.9)$ \\
\hline
\end{tabular}

lower than placenta). 42 samples had low to very low PRL mRNA level (100-2,000-fold lower than placenta) and 18 samples had values at the border of the detection limit (20,000-fold lower than placenta). Supplementary Table $1 \mathrm{~S}$ shows the individual $\mathrm{Ct}$ and deltaCt values for all samples.

The sensitivity of the assay was improved by preamplification of PRL and ACTB with 14 PCR cycles prior to running qPCR analysis (Supplementary Table $1 \mathrm{~S}$ (A). The results confirmed that many samples indeed exhibited insignificant PRL signals. Control qPCR to detect the cancer marker genes PLAU and PLAUR with Array II showed that the cDNA quality and quantity was sufficient for detection of the analysed genes. In addition, all analysed samples showed PRLR mRNA expression.

Furthermore, qPCR analysis was used to examine PRL mRNA expression in 14 human breast cancer cell lines (Table 2). The PRL mRNA level in T47D cells was about 20,000-fold lower than that in placenta and corresponded to the expression level in 18 breast cancer tissue samples with values near the detection limit. In all the other tested breast cancer cell lines, PRL values were extremely low or undetectable. In contrast, all tested cell lines showed high to medium levels of PRLR mRNA, while the cancer markers PLAU and PLAUR (encoding uPA receptor) displayed mRNA medium to low mRNA levels. In summary, we conclude that a majority of breast cancer samples as well as breast cancer cell lines have very low to negligible levels of PRL mRNA, and that only in very rare instances higher PRL mRNA levels can be found.

Analysis of PRL mRNA expression in human breast carcinomas and cell lines at the cellular level by ISH

As a positive control, the ISH technique for PRL detection was first tested using the pituitary gland and placenta, both tissues well known to express PRL. ISH readily detected PRL mRNA expression in tissue sections of pituitary gland (Fig. 1a, b, a',b') and after prolonged exposure time (8 weeks compared to 2 weeks for pituitary gland) PRL mRNA expression was also easily detected in tissue sections of human placenta (Fig. 1d, e, d', e'), confirming results by Gellersen et al. [12]. Whereas PRL is expressed at high levels in pituitary gland for endocrine purposes, PRL expression in placenta rather has autocrine/paracrine function and is thus a relevant positive control for the reported autocrine/paracrine expression of PRL in human breast cancers.

The PRL sense probe (used as a negative control for unspecific binding and binding of probes to genomic DNA) did not generate detectable hybridization signals on any of the sections tested, confirming specific hybridization of the probes under the conditions used (Fig. 1c, c', f, f'). As an additional control for specificity of the hybridization of the long PRL cRNA probe (507 bp), two shorter probes (196 and $222 \mathrm{bp}$ ) representing non-overlapping regions of the PRL gene demonstrated the same hybridization signals of similar intensity as the longer probe on pituitary gland (Supplementary Fig. 1s) thus validating the specificity of the ISH procedure employed in the present study to detect PRL mRNA transcripts.

Moreover, to verify that the tissue samples used in the present study were suitable for the ISH application, ISH was performed with a ${ }^{35} \mathrm{~S}$-labelled cRNA probe representing the cancer marker gene PLAU-1 (encoding uPA protein). Expression of this gene in human breast cancer has previously been demonstrated by ISH [24]. Accordingly, we obtained a positive-ISH signal with the PLAU-1 probe in all 19 samples of human breast carcinoma included in this study (Supplementary Fig. 2s). The origin of these samples is described in the Materials and Methods 
Table 2 qPCR analysis of breast cancer cell lines

\begin{tabular}{|c|c|c|c|c|c|}
\hline & PRL & PRLR & PLAU-1 & PLAUR-1 & ACTB \\
\hline T47D & 36.1 & 22.0 & 35.3 & 32.4 & 21.3 \\
\hline MDA-MB361 & 39.6 & 23.2 & 34.0 & 35.0 & 20.3 \\
\hline AU565 & 38.5 & 26.4 & 40.1 & 28.3 & 20.5 \\
\hline BT20 & Undetermined & 30.8 & 35.5 & 27.0 & 20.3 \\
\hline BT474 & Undetermined & 24.9 & 35.7 & 37.4 & 20.9 \\
\hline BT549 & Undetermined & 29.0 & 25.6 & 25.1 & 19.7 \\
\hline MCF-7 & Undetermined & 25.9 & 35.3 & 30.2 & 21.4 \\
\hline MDA-MB157 & 34.4 & 28.1 & 30.5 & 28.3 & 20.7 \\
\hline MDA-MB175 VII & 41.0 & 27.1 & 34.5 & 30.9 & 22.1 \\
\hline MDA-MB231 & Undetermined & 31.0 & 26.2 & 27.3 & 21.5 \\
\hline MDA-MB468 & 39.5 & 28.3 & 31.8 & 26.4 & 20.8 \\
\hline SK-BR-3 & Undetermined & 27.0 & 31.5 & 30.3 & 21.6 \\
\hline ZR-75-1 & 37.1 & 26.5 & 37.2 & 28.5 & 20.2 \\
\hline MFM 223 & 40.9 & 25.8 & 34.6 & 33.2 & 21.6 \\
\hline $\mathrm{Ct}$ range & 34.4-undetermined & $22-31$ & $25.6-40.1$ & $25.1-37.4$ & $19.7-22.1$ \\
\hline
\end{tabular}

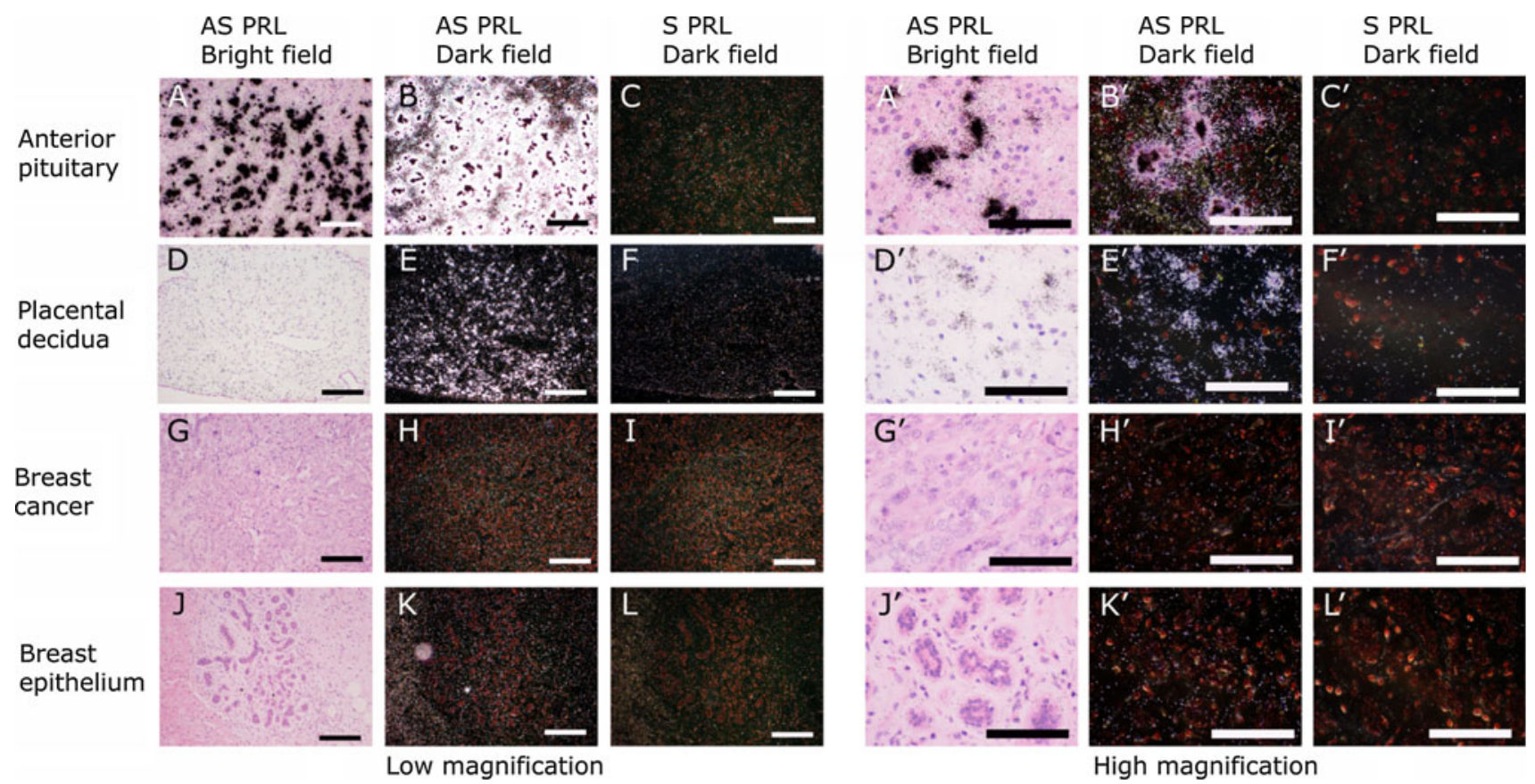

Fig. 1 Analysis of PRL mRNA expression in the pituitary gland, placenta, breast carcinoma and adjacent normal breast tissue by ISH. Bright field and dark field pictures are shown. A 507 bp PRL cRNA antisense probe (AS PRL) was hybridized onto sections of paraffinembedded anterior pituitary, placental decidua, invasive ductal carcinoma of the breast and adjacent normal breast epithelium tissues as indicated. Additional adjacent sections were hybridized with PRL sense probe (S PRL) as a negative control. Signal is visualised under

section and the clinicopathological characteristics of the patients are listed in Supplementary Table 2S.

We then analysed PRL mRNA expression in these 19 human breast cancer samples. In none of them we were dark field as white grains. Bright field represents the haematoxylin and eosin stained sections after hybridization with PRL antisense probe. Under bright field ISH signal is visualised as black grains. Sections of anterior pituitary tissue were developed after 2 weeks of exposure whereas the other tissue sections were developed after 8 weeks of exposure. Representative pictures are shown at both low and high magnification (left and right panel, respectively). Scale bars $=100 \mu \mathrm{m}$

able to detect expression of PRL mRNA by the ISH technique (Fig. 1g, h, g', h' and data not shown). Importantly, these data show that PRL mRNA expression was not induced in a minor subset of human breast cancer cells 


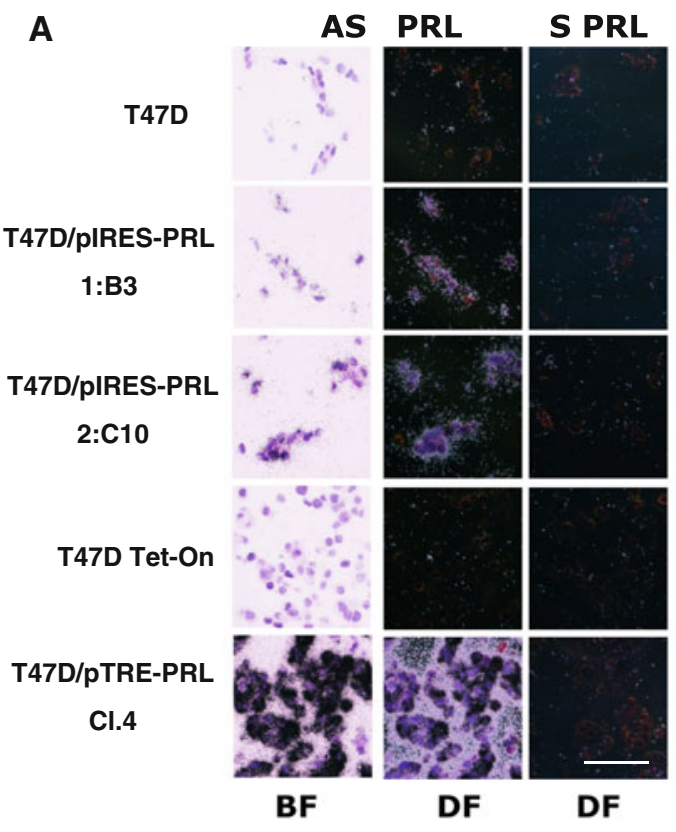

Fig. 2 Establishment of T47D/PRL clones with high levels of ectopic PRL expression a ISH analysis of PRL mRNA expression in wild type and PRL-transfected cell lines. Bright field (BF) and dark field (DF) pictures are shown. Sections of paraffin-embedded cells were hybridized with an antisense cRNA probe (507 bp) complementary to the PRL mRNA (AS PRL). Signal is visualised under DF as white grains. BF represents the haematoxylin and eosin stained sections after hybridization with AS PRL probe to show morphology of the cells. Under BF ISH signal is visualised as black grains. Lack of detectable hybridization signal with sense probe (S PRL) indicates specificity of signals obtained with the PRL AS probe. Sections were developed after 2 weeks of exposure. Scale bars $=100 \mu \mathrm{m}$. b Analysis of the PRL protein expression. Cells were grown to 70-80\% confluence in $10 \%$ FCS medium and then starved for $24 \mathrm{~h}$ in serum-

within the same tumour, which might not have been detected by the qPCR technique. Adjacent normal breast epithelium, present in some of the cancer tissue samples, likewise expressed PRL mRNA at levels below the detection limit of the assay (Fig. 1j, k, j', k' and data not shown). Supporting these data, PRL mRNA expression was also not observed when ISH was performed on human breast cancer tissue microarray (TMA) slides from commercial sources representing tumours from 84 breast cancer patients (data not shown).

Finally, a small panel of human breast cancer cell lines was analysed for PRL mRNA expression by the ISH technique. None of the tested cells (T47D, AU565, MDAMB157, BT483, and ZR-75-1) expressed detectable levels of PRL mRNA (Fig. 2a and data not shown).
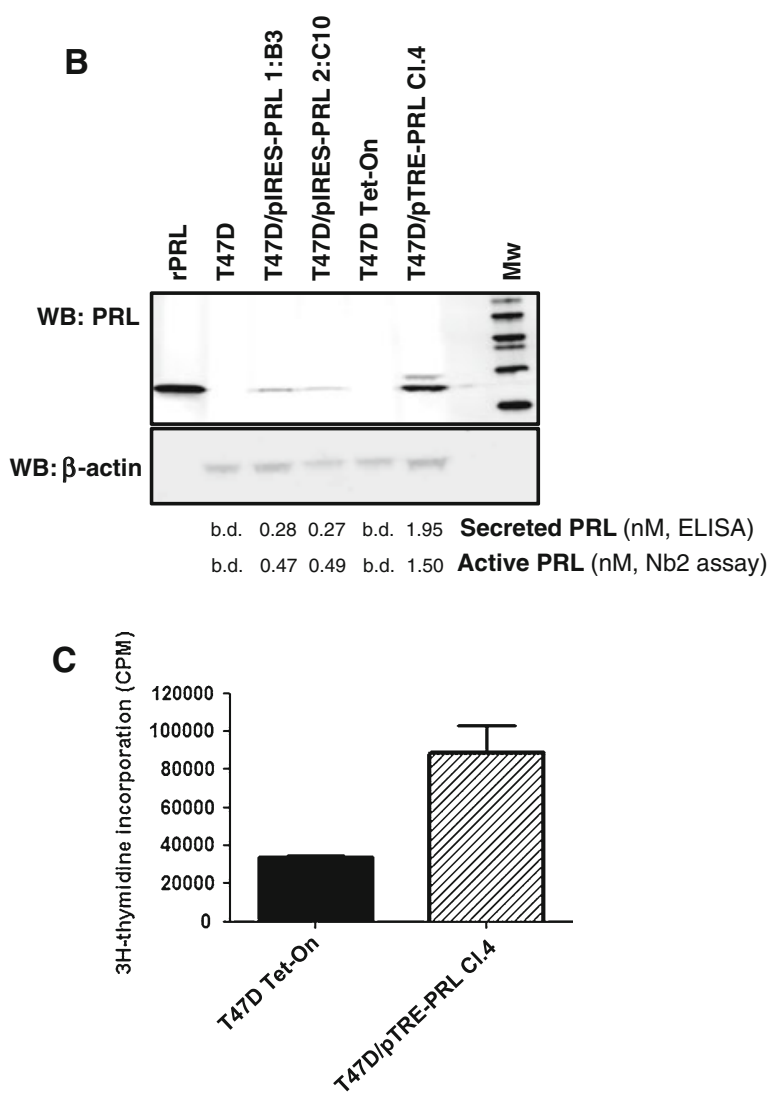

free DMEM medium. $20 \mu \mathrm{g}$ of cellular protein extracts were analysed by Western blotting using a PRL-specific antibody (top panel); $\beta$ actin was used as protein loading control (lower panel). Supernatants were analysed for secreted and active PRL using ELISA and Nb2 proliferation, respectively. The PRL level is stated as nmoles/1 mio cells/24 h. b.d. below detection limit. $\mathbf{c}$ Transwell co-culture of T47D and T47D/PRL cells. T47D Tet-On cells were seeded in 24-well multi-dishes in $10 \%$ CSS medium. After $24 \mathrm{~h}$ of plating, inserts with either T47D Tet-On or T47D/pTRE-PRL Cl.4 cells were placed on top of T47D Tet-On cells. After three days of culture, inserts were discarded. The PRL level in the medium was analysed by ELISA, while proliferation of T47D Tet-On cells was measured using ${ }^{3} \mathrm{H}-$ thymidine incorporation. Mean $\pm \mathrm{SD}$ of four independent wells are shown

Establishment of T47D clones secreting PRL

In order to mechanistically address a putative tumour growth-promoting role of the autocrine PRL, which was suggested in a number of published studies, we ectopically expressed PRL in human breast tumour cells and studied their phenotype. As we previously detected a high PRLR expression level in T47D cells [Table 2; 25] and the cells demonstrated a significant proliferative response to exogenous recombinant PRL [6], this cell line was chosen for the study. Expression of endogenous PRL in these cells was very low/negligible on the RNA level (Fig. 2a; Table 2) and not detectable on the protein level (Fig. 2b). Therefore, we stably transfected T47D cells as well as their established subclone, T47D Tet-On, with either pIRESneo2-hPRL 
vector for constitutive expression of PRL or pTRE2hyg2hPRL for Tet-inducible expression of PRL, respectively. Two T47D/pIRES-PRL clones (1:B3 and 2:C10) and one T47D/pTRE-PRL clone (Cl.4) were selected for the analysis. Transcription of PRL was detected by ISH (Fig. 2a). Expression of the PRL protein was confirmed by Western blotting (Fig. 2b). The majority of the PRL protein expressed by transfected T47D cells appeared to have the same electrophoretic mobility as the recombinant PRL produced in E.coli, i.e. did not seem to be glycosylated. However, a band of unknown identity with a lower electrophoretic mobility can also be detected in Cl.4. Secretion of PRL was analysed in serum-free conditioned media for the total and biologically active protein using ELISA and an $\mathrm{Nb} 2$ cell proliferation assay, respectively (Fig. 2b). The latter assay is widely used to quantify biologically active PRL capable of inducing proliferation of lactotroph-dependent $\mathrm{Nb} 2$ cells $[21,26]$. We found a good correlation between the expression levels of PRL mRNA, total PRL protein, secreted PRL and bioactive PRL in the analysed cells. Cl.4 was found to express a significantly higher level of PRL than 1:B3 and 2:C10 clones. Expression of PRL in the two control T47D cell lines was undetectable by any of the above mentioned assays. However, a very low PRL transcription level was detected in T47D cells by qPCR (see previous section; Table 2). If these cells were capable of secreting any PRL protein, its amount was below detection limits of the ELISA and $\mathrm{Nb} 2$ assays, which was estimated to correspond to $47 \mathrm{pg} / 10^{6}$ cells $/ 24 \mathrm{~h}$ and $69 \mathrm{pg} / 10^{6}$ cells $/ 24 \mathrm{~h}$, respectively. Noteworthy, despite the T47D Tet-On cell line is designed to be an inducible gene expression system, where the gene of interest is expressed only in the presence of doxycycline, PRL was constitutively produced by the T47D/pTRE-PRL clone $\mathrm{Cl} .4$ and no major induction of PRL expression was observed by addition of doxycycline (data not shown). Therefore, in this study the T47D/pTRE-PRL Cl.4 was used as a constitutive PRL expressing cell line without doxycycline induction.

We further examined the potential of the secreted and ectopically expressed PRL to stimulate proliferation of breast cancer cells in a paracrine manner. T47D Tet-On cells were co-cultured in transwell chambers with T47D/ pTRE-PRL Cl. 4 cells, or as control, T47D Tet-On cells for three days. In the T47D Tet-On: T47D/pTRE-PRL Cl. 4 co-culture, the PRL content in the medium was $5.1 \mathrm{nM}$ as measured by ELISA. Proliferation of T47D Tet-On cells was stimulated by approximately 2.5 -fold as compared to the T47D Tet-On:T47D Tet-On control co-culture for which the PRL level in the medium was below detection limit of the ELISA assay (Fig. 2c). Thus, ectopically expressed PRL can promote growth of breast cancer cells in a paracrine fashion.
Ectopic PRL reduces proliferation of T47D/PRL cells

To address the effect of endogenous PRL on breast cancer cell growth, we counted T47D and T47D/PRL cells during seven days of culture. The cells were maintained in phenol red-free DMEM medium supplemented with either $10 \%$ FCS or $10 \%$ charcoal/dextran-stripped FCS (referred as $10 \%$ CSS). We have previously shown that under the latter conditions recombinant PRL stimulated proliferation of T47D cells (Rasmussen et al. 2010). Surprisingly, lower cell numbers were evident in all T47D/PRL clones as compared with the two control T47D cell lines (Fig. 3a, b). A similar result was obtained when cell proliferation was measured by ${ }^{3} \mathrm{H}$-Thymidine incorporation (Fig. 3c, d).

In order to analyse the antiproliferative effect of ectopically expressed PRL, we investigated whether PRL affected specific cell cycle phases. The $\mathrm{G}_{0} / \mathrm{G}_{1}$ fraction was increased in T47D/PRL clones as compared to the control T47D cells (Fig. 3e), indicating that ectopic expression of PRL causes $\mathrm{G}_{0} / \mathrm{G}_{1}$ cell cycle arrest. In line, expression of Cyclin D1 protein, a critical regulator of $\mathrm{G}_{1}$ passage, was decreased in the T47D/PRL clones as compared to the control T47D cell lines (Fig. 3f). No significant changes in the expression level of the anti-apoptotic protein Bcl-2 was observed in T47D/ PRL cells as compared to the control T47D cells, indicating that T47D/PRL cells were not more prone to the apoptosis pathway that is controlled by Bcl-2. Taken together, our data suggest that ectopic expression of PRL may inhibit Cyclin D1 expression, cell cycle progression, DNA replication and hence the division of T47D breast cancer cells.

\section{Ectopic PRL down-regulates PRLR expression} and signalling capacity

To further characterise the T47D/PRL clones we examined the PRLR expression level (Fig. 4a). Flow cytometry analysis revealed a reduced PRLR level on the cell surface of T47D/PRL cells as compared to the control T47D cells. In line, we also found a lower total PRLR protein level in PRL-producing cells as compared to the control T47D cells using Western blot analysis.

We further investigated the signalling response of T47D/PRL cells to the exogenous recombinant PRL (rPRL). The ERK1/2 pathway was proposed to play a key role in PRL-induced T47D proliferation [27]. As expected, rPRL activated the ERK1/2 signalling pathways in the control T47D cells. Meanwhile, no/weak ERK1/2 stimulation was observed in T47D/PRL cells (Fig. 4b).

We previously demonstrated that rPRL and estrogen synergistically stimulated cell proliferation [6]. Here, we tested whether ectopic PRL similarly co-stimulates estrogen-induced T47D/PRL proliferation. No differences in 
A
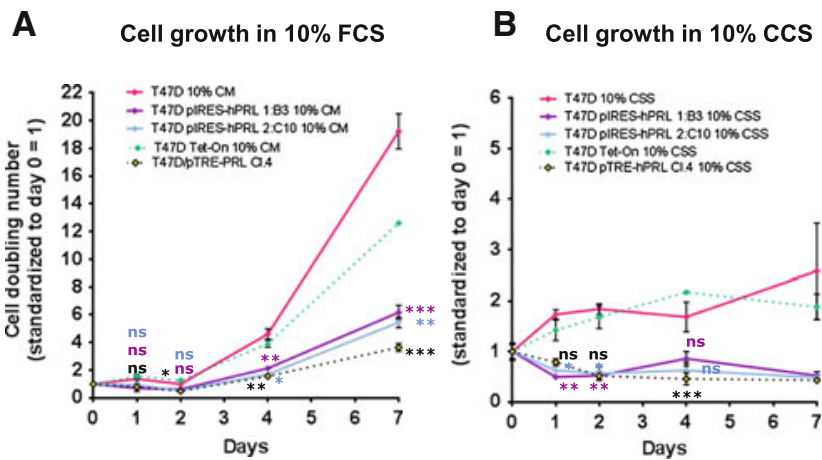

$\mathbf{E}$

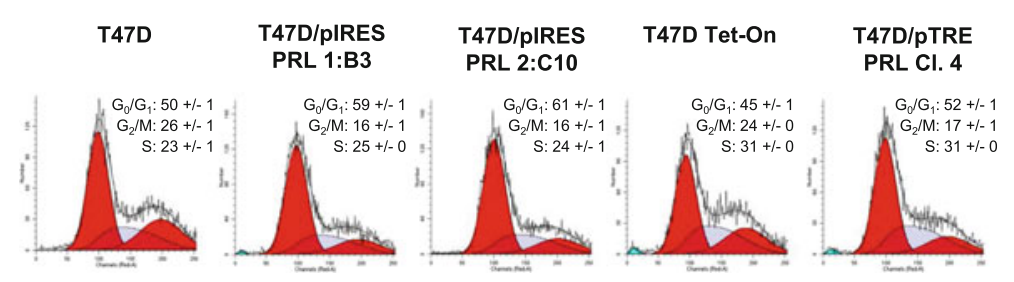

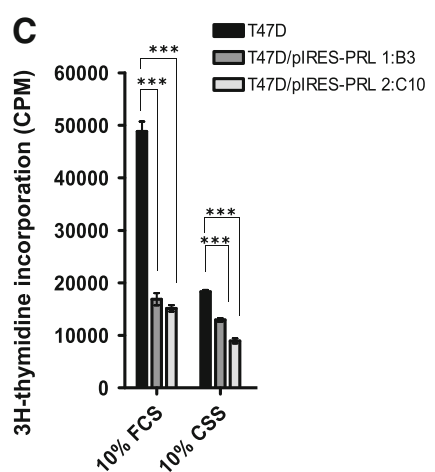
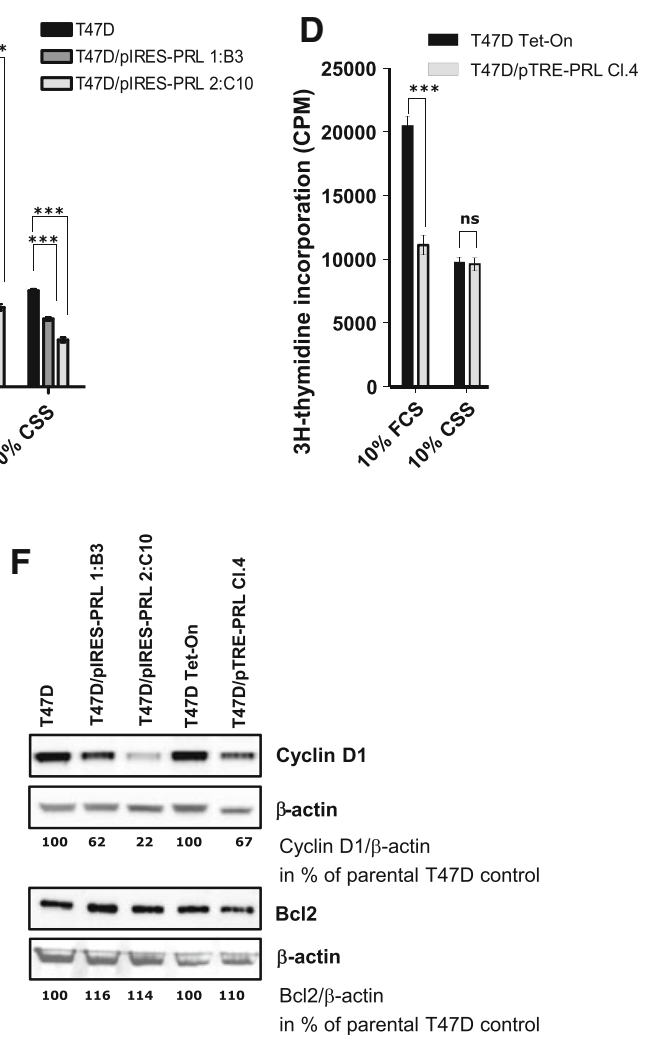

Fig. 3 Ectopically expressed PRL reduces proliferation of T47D cells a, b Growth of T47D/PRL clones. Cells were seeded with a density of $4.8 \times 10^{4}$ cells/well in a 24-well multi-dish in $10 \%$ FCS medium (a) or $10 \%$ CSS medium (b). Cell numbers were determined at the indicated days of culture. Mean $\pm \mathrm{SD}$ of three independent wells are shown; $\mathbf{c}, \mathbf{d}$ Proliferation of T47D/PRL clones. Cells were plated with a density of $1.2 \times 10^{4}$ cells/well in a 96-well multi-dish in $10 \%$ FCS medium, $10 \%$ CSS medium or serum-free DMEM medium. Cell proliferation was estimated after three days of culture by measuring DNA synthesis using ${ }^{3} \mathrm{H}$-thymidine incorporation. Mean \pm SD of six independent wells are shown; statistics is shown: $* * * p<0.001 ; * * p<0.05 ; * p<0.01$; ns, $p>0.01$ ( $t$ test). e Cell cycle analysis of T47D/PRL clones. Cells $\left(6 \times 10^{5}\right)$ were plated in a 6-well multi-dish in $10 \%$ FCS medium and cultured for three days.

oestrogen-induced proliferation was observed between transfected and wild type cells suggesting that ectopically expressed PRL does not enhance the mitogenic effect of oestrogen. In addition, exogenous rPRL did not further promote proliferation of the oestrogen-stimulated T47D/ PRL cells (Fig. 4c). Together, these results indicate that the T47D/PRL cells being constantly exposed to PRL downregulated the PRLR expression and its signalling capacity, which may at least in part explain the lack of a proliferative response to endogenous and exogenous PRL.

\section{Discussion}

A number of studies have shown that PRL and its receptor are co-expressed in breast cancer tissue and cell lines and
DNA of cells was stained with propidum iodide, analysed by flow cytometry and quantified using ModFit. Debris and doublets were excluded by FSC/SSC gating. $\mathrm{G}_{0} / \mathrm{G}_{1}$ and $\mathrm{G}_{2}-\mathrm{M}$ populations are illustrated in red; the dashed grey field is the $\mathrm{S}$ phase. The DNA content is shown in percent $\pm \mathrm{SD}$ of three independent wells; f Cyclin D1 and Bcl-2 protein expression in T47D/PRL clones. Cells were cultured for five days in $10 \%$ FCS medium till $\sim 80 \%$ confluence. $20 \mu \mathrm{g}$ of cellular protein were analysed by Western blotting using Cyclin D1 and Bcl-2 specific antibodies. $\beta$-actin was used as a protein loading control. The signals of Cyclin D1 and Bcl-2 were quantified and normalised by the $\beta$-actin signals. The numbers represent percentage of the respective control T47D cell line values. A representative of three independent experiments is shown

thus PRL has been suggested to promote growth of the carcinomas in an autocrine/paracrine fashion [10, 14]. Immunostaining (immunohistochemistry (IHC) or Western blotting) was used to detect the PRL protein expression in several studies $[13,28]$. However, detection of the PRL protein in tissues and cultured cells can be confounded by the fact that cells can sequester PRL from serum or culture medium. Foetal bovine serum present in cell culture medium contains bovine PRL, which shares 75/85\% identity/similarity to human PRL, thus human and bovine PRL would be indistinguishable by common immunoassays. PRL has been detected in the epithelial cells of the lactating mammary gland and in milk. Sequestration of PRL from the circulation was demonstrated in vivo by tracing radiolabelled PRL from blood to milk and in vitro by following the transit of intact PRL through breast 


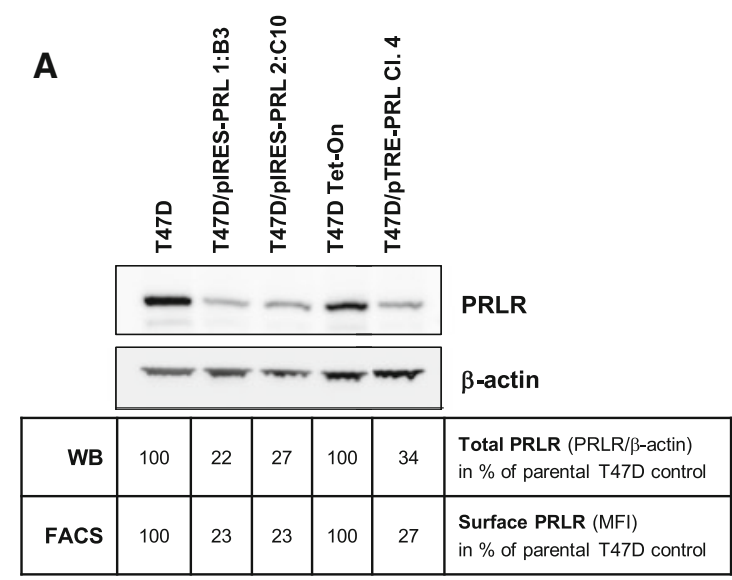

B

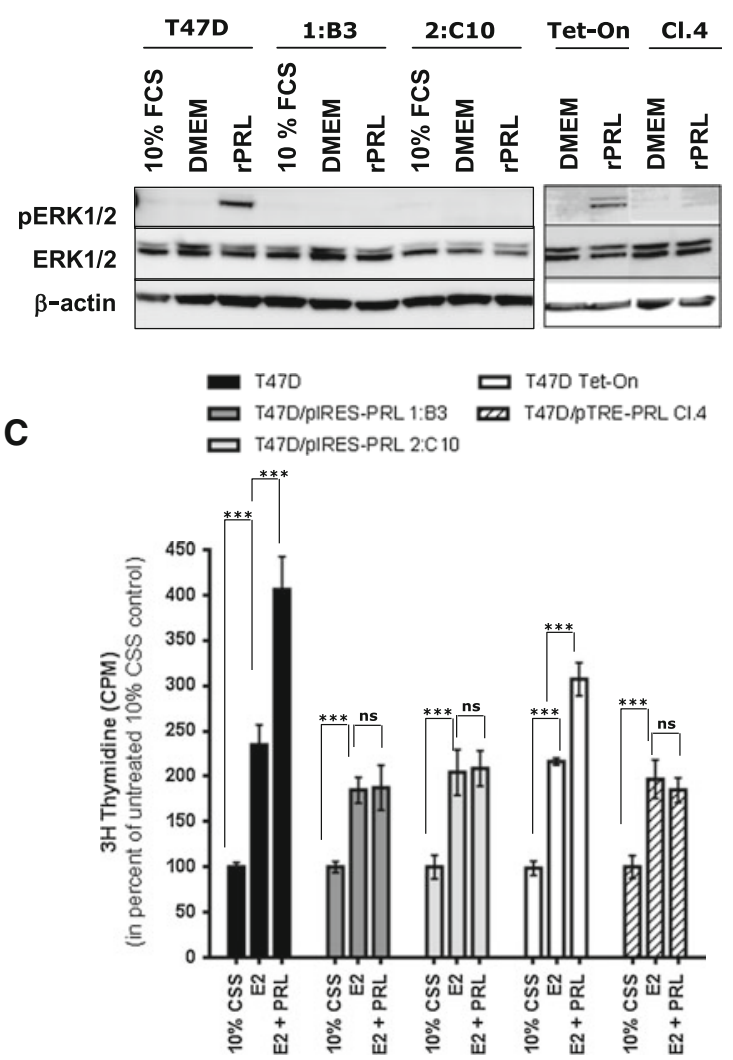

Fig. 4 Ectopically expressed PRL down-regulates PRLR expression and responsiveness to exogenous rPRL stimulation a PRLR protein expression in T47D/PRL cells. Cells were harvested at 70-80\% confluence and $40 \mu \mathrm{g}$ protein extracts were analysed by Western blotting using an anti-human PRLR antibody. $\beta$-actin was used as protein loading control. The signals of PRLR were quantified and normalised by the $\beta$-actin signals. The numbers represent a percentage of the respective control T47D cell line. Expression of PRLR on the surface of the cells was analysed by flow cytometry (FACS). Cells were stained with an anti-human PRLR mAb followed by anti-mouse IgG-APC. The median fluorescent intensities (MFI) are shown. b Cell signalling induced by rPRL. Cells were grown to 70-80\% confluence in $10 \%$ FCS medium and starved in serum-free DMEM medium for $24 \mathrm{~h}$ prior to treatment with $20 \mathrm{nM}$ rPRL for $30 \mathrm{~min}$. $20 \mu \mathrm{g}$ of protein

epithelial cells [11]. Similar data have been reported for placental trophoblast [29] suggesting that uptake of PRL is a wide-spread phenomenon. Thus, the conclusion that the PRL protein is locally synthesised in tissues cannot be drawn based on the IHC staining and Western blotting. To the best of our knowledge, production of PRL by cancer cells has been directly demonstrated only in a single study by Ginsburg and Vonderhaar [16]: de novo PRL synthesis in the MCF7 and the oestrogen receptor-negative variant of T47D (T47Dco) breast cancer cell lines has been demonstrated by inhibiting the effects of PRL from cell culture supernatants by anti-PRL antibodies. In contrary, more recent studies did not show any growth-inhibitory effect of PRL antagonists under standard growth conditions using

extracts were analysed for activation of the ERK1/2 pathway by Western blotting using an anti-pERK1/2 antibody. Membranes were stripped and sequentially re-probed with antibodies detecting total ERK1/2 protein and $\beta$-actin as loading controls. $\mathbf{c}$ Proliferation of T47D/PRL cells upon E2 and PRL exposure. Cells were seeded with a density of $1.2 \times 10^{4}$ cells/well in 96-well multi-dishes in $10 \%$ CSS medium. Next day, medium was renewed and cells were cultured for three days in absence or presence of $1 \mathrm{nM} \mathrm{17 \beta -estradiol} \mathrm{(E2)} \mathrm{and} 20$ $\mathrm{nM} \mathrm{rPRL}$ as indicated. Cell proliferation was estimated by measuring DNA synthesis using ${ }^{3} \mathrm{H}$-thymidine incorporation and stated in percent of $10 \%$ CSS control for each cell line. Mean \pm SD of six independent wells are shown for a representative of three independent experiments. Statistics is shown: $* * * p<0.001 ; \quad * * p<0.05$; $* p<0.01 ; \mathrm{ns}, p>0.01$ ( $t$ test)

T47Dco cells [30] or MCF-7, T47D, MDA-MB-453, MDA-MB-468 and SK-BR3 cells [31].

Expression of PRL mRNA in invasive human breast carcinomas and breast cancer cell lines has been demonstrated using either ISH with biotinylated primers $[14,17]$ or RT-PCR followed by Southern blotting [13-15, 18], which led to a conclusion that significant PRL expression is common in human breast carcinomas.

In the present study, a qPCR analysis with validated primers from Applied Biosystems was performed on a selection of breast cancer cell lines, as well as on commercially available cDNA arrays covering 144 breast cancer biopsies. Our analysis showed that the majority of the cell lines and biopsy samples had very low to negligible 
levels of PRL mRNA. Only one biopsy cDNA sample had a relatively high PRL level, similar to that found in placenta and eight samples showed low PRL mRNA levels (8-32-fold lower than placenta).

Further, an ISH procedure was developed to analyse PRL mRNA expression at the cellular level in clinical samples of breast cancers. The method was validated in several ways: 1) hybridization to T47D/PRL clones demonstrated the ability of the technique to detect exogenously expressed PRL mRNA; 2) positive control tissues (pituitary gland and placenta) were included to demonstrate detection of endogenous levels of PRL mRNA expression; 3) two non-overlapping cRNA probes were shown to give identical hybridization signal on positive control tissues demonstrating specific detection of the PRL transcripts; 4) complementary sense probes did not give any hybridization signals, again demonstrating specific hybridization using the current method; 5) a PLAU-1 probe was used as a positive control to demonstrate that the clinical breast cancer samples included in the present study were suitable for use in the ISH application. Using this well-validated ISH procedure we were unable to demonstrate detectable PRL mRNA expression in neither clinical breast cancers nor in a small panel of human breast cancer cell lines. This result supports the data generated by qPCR and strongly suggests that PRL mRNA expression is not induced in a minor subset of human breast cancer cells within the same tumour, which might have been missed using the qPCR technique. In contrast, Clevenger and co-workers have previously reported that PRL was highly expressed in human breast tumours using an alternative ISH protocol $[14,17]$. They applied non-complementary sense and antisense oligonucleotide probes that were originally designed for use as PCR primers. Unfortunately, validation of these probes in the ISH application was not described in any of the two papers.

It is noteworthy that our data on the lack of up-regulation of PRL mRNA expression in the majority of the analysed breast cancer samples are in a full agreement with the data available from expression databases, including Oncomine (an example is given in Supplementary Fig. 3S).

While we found a low/very low level of PRL mRNA expression in few breast cancer cell lines including T47D cells when maintained under standard growth conditions by the qPCR analysis, the PRL protein secretion by these cells was below detection limit of ELISA or an $\mathrm{Nb} 2$ assay. Significant correlation was also not observed between the PRL mRNA expression and immunohistochemical localisation of the PRL protein in the previous study by Bhatavdekar et al. [13], indicating that the presence of PRL mRNA does not necessarily point to the presence of the PRL protein.

The T47D cell line is commonly used to study effects of PRL in vitro due to the high PRLR expression level and a significant ligand-induced signalling response. To investigate the putative mechanism of an autocrine/paracrine loop, we used T47D cells transfected with PRL as a model. Interestingly, while exogenous rPRL stimulated T47D growth [6], proliferation was reduced upon ectopic PRL expression. Cyclin D1 expression, DNA synthesis and cell division were decreased in three different T47D/PRL clones as compared to the control T47D cells. The decrease in the proliferation rate could potentially be caused by several factors, including apoptosis, cell senescence, endoplasmic reticulum stress upon ectopic expression of PRL and downregulation of the PRLR expression. The anti-apoptotic protein $\mathrm{Bcl}-2$ was previously suggested to be involved in PRL-mediated cell survival [32]. We observed no significant changes in $\mathrm{Bcl}-2$ protein expression in T47D/ PRL versus control T47D cells indicating that endogenous PRL may not influence the apoptotic pathway that is inhibited by Bcl-2. Despite a high level of senescenceassociated $\beta$-galactosidase activity observed in PRL-producing clones (data not shown), it does not seem likely that T47D/PRL cells had turned into senescence, as they were still responsive to oestrogen. In addition, we were not able to confirm a senescence phenotype, which is characterised by the expression of several markers, including pATM, $\gamma \mathrm{H} 2 \mathrm{AX}, \mathrm{p} 21$ or p16-INK4a (data not shown). The reduced growth of PRL-expressing cells also does not seem to be due to the endoplasmic reticulum stress upon synthesis and folding of PRL since grp78/BiP, a major sensor of endoplasmic reticulum stress, was not up-regulated in T47D/ PRL cells (data not shown).

A number of studies have shown a correlation between decreased PRLR level and reduced cell proliferation. Oakes et al. [7] have demonstrated reduced cell proliferation of pre-invasive lesions and hence delayed tumour formation in PRLR knock-out mice. A decreased number of T47D cells were found upon ectopic expression of the PRLR short splice isoform that presumably acted as a signallingincompetent decoy receptor [33]. Down-regulation of the PRLR expression by shRNA reduced the growth, invasiveness and tumourigenicity of T47D cells [34]. Furthermore, stabilized PRLR was shown to contribute to accelerated proliferation and invasive growth of normal breast epithelial cells [34]. In the present study, we found a reduced PRLR protein level in PRL-producing cells, which at least in part could explain the observed reduction in the cell proliferation rate. Besides PRL-induced receptor signalling, functional effects of ligand-independent PRLR dimerization were reported [35]. Moreover, it was recently demonstrated that growth hormone $(\mathrm{GH})$ induces PRLRmediated rather than $\mathrm{GH}$ receptor-mediated signalling in T47D breast cancer cells [36]. Thus, the molecular mechanism of the tumour growth promoting effect of PRLR seems to be quite complex and still remains to be elucidated. 
In contrast to our findings in T47D cells, increased PRLR level and cell proliferation rate were reported in MDA-MB-435 cells with constitutive ectopic expression of PRL [22] and in MCF7 cells with a tetracycline-inducible PRL expression [21]. The discrepancy between these results and our findings may be due to differences in the basal PRLR level. Unlike MCF7 and MDA-MB-435, T47D cells express PRLR at a relative high level. It was described for other growth factor receptors that a high number of cell surface receptors caused cell differentiation upon ligand-mediated activation, while a lower number resulted in a proliferative response $[37,38]$. The duration of the exposure of cells to PRL may influence the expression level and signalling capacity of PRLR. We were able to stimulate proliferation of T47D cells by treatment with the recombinant PRL for 3-5 days [6]. The inducible expression of PRL in MCF7 cells described by Gutzman et al. [21] resembles such a set-up with a relatively short exposure of the cells to PRL. In contrast, our transfected T47D cells expressed PRL constitutively, which might have contributed to the lack of responsiveness to PRL ('tolerance phenotype').

Moreover, a clear difference in the expression level and activity of transcription factors has been demonstrated among diverse breast cancer cell lines [39]. In MCF7 cells, PRL induced a profound activation of AP-1, while activation of the GAS element was minor. In contrast, PRL did not stimulate AP-1 activity in T47D cells, while a profound activation of GAS was evident.

Since exogenous PRL was shown to promote growth of breast tumours and breast cancer cell lines, the endogenously expressed PRL was proposed to exert similar effects. Interestingly, exogenous and autocrine hormones may indeed act differently. A clear discrepancy in gene regulation was evident in case of autocrine and exogenously applied GH [40]. Microarray analysis of 19,000 genes identified only 167 genes commonly regulated by exogenous and endogenous GH in human breast cancer cells. Changes in the expression level of 305 genes in response to endogenous vs. exogenous $\mathrm{GH}$ were remarkably different. As compared to the endogenous $\mathrm{GH}$, the exogenous GH preferentially up-regulated the expression of genes, which are grouped within the Gene Ontology categories of Cell Cycle, Signal Transduction, Metabolism, Transport and Development. A similar thorough study comparing effects of exogenous versus endogenous PRL on gene expression has not yet been performed. So far, only one study by Gutzman et al. [21] reported differential effects of the exogenous and endogenous PRL on the regulation of the PRLR and oestrogen receptor protein expression. Our data are in agreement with the recently published work by Ferraris et al. [41], showing that autocrine PRL may mediate anti-proliferative effects in mouse anterior pituitary. In conclusion, we show that (1) PRL is expressed at very low levels in breast tumours and (2) ectopic PRL expression inhibits T47D breast cancer cell proliferation. Even though our findings from in vitro mechanistic studies cannot be extrapolated to a complex tumour growth regulation in clinical cancers, the clinical data presented here indicate that autocrine PRL signalling is not a general mechanism promoting breast cancer cell growth.

Acknowledgements The authors thank Lise F. W. Jensen, Jette W. Platou, Corinne Weideli Hansen, Anja Jensen, Tine Ø. Pedersen, Jette Mandelbaum and Birte Jørgensen for excellent technical assistance. LMN PhD fellowship was in part supported by the Danish Agency for Science Technology and Innovation and MWB was supported by the Danish Research Council.

Conflict of interest The authors declare that there is no conflict of interest that could be perceived as prejudicing the impartiality of the research reported.

Open Access This article is distributed under the terms of the Creative Commons Attribution Noncommercial License which permits any noncommercial use, distribution, and reproduction in any medium, provided the original author(s) and the source are credited.

\section{References}

1. Hennighausen L, Robinson GW (2005) Information networks in the mammary gland. Nat Rev Mol Cell Biol 6:715-725

2. Swaminathan G, Varghese B, Thangavel C, Carbone CJ, Plotnikov A, Kumar KG, Jablonski EM, Clevenger CV, Goffin V, Deng L, Frank SJ, Fuchs SY (2008) Prolactin stimulates ubiquitination, initial internalization, and degradation of its receptor via catalytic activation of Janus kinase 2. J Endocrinol 196:R1-R7

3. Tworoger SS, Hankinson SE (2008) Prolactin and breast cancer etiology: an epidemiologic perspective. J. Mammary. Gland. Biol. Neoplasia. 13:41-53

4. Gonzalez L, Zambrano A, Lazaro-Trueba I, Lopez E, Gonzalez JJ, Martin-Perez J, Aranda A (2009) Activation of the unliganded estrogen receptor by prolactin in breast cancer cells. Oncogene 28:1298-1308

5. Chen WY, Ramamoorthy P, Chen N, Sticca R, Wagner TE (1999) A human prolactin antagonist, hPRL-G129R, inhibits breast cancer cell proliferation through induction of apoptosis. Clin Cancer Res 5:3583-3593

6. Rasmussen LM, Frederiksen KS, Din N, Galsgaard E, Christensen L, Berchtold MW, Panina S (2010) Prolactin and oestrogen synergistically regulate gene expression and proliferation of breast cancer cells. Endocr Relat Cancer 17:809-822

7. Oakes SR, Robertson FG, Kench JG, Gardiner-Garden M, Wand MP, Green JE, Ormandy CJ (2007) Loss of mammary epithelial prolactin receptor delays tumor formation by reducing cell proliferation in low-grade preinvasive lesions. Oncogene 26: 543-553

8. Rose-Hellekant TA, Arendt LM, Schroeder MD, Gilchrist K, Sandgren EP, Schuler LA (2003) Prolactin induces ERalphapositive and ERalpha-negative mammary cancer in transgenic mice. Oncogene 22:4664-4674

9. Wennbo H, Gebre-Medhin M, Gritli-Linde A, Ohlsson C, Isaksson OG, Tornell J (1997) Activation of the prolactin receptor but not the 
growth hormone receptor is important for induction of mammary tumors in transgenic mice. J Clin Invest 100:2744-2751

10. Ben-Jonathan N, Liby K, McFarland M, Zinger M (2002) Prolactin as an autocrine/paracrine growth factor in human cancer. Trends Endocrinol Metab 13:245-250

11. Ben-Jonathan N, Mershon JL, Allen DL, Steinmetz RW (1996) Extrapituitary prolactin: distribution, regulation, functions, and clinical aspects. Endocr Rev 17:639-669

12. Gellersen B, DiMattia GE, Friesen HG, Bohnet HG (1989) Prolactin (PRL) mRNA from human decidua differs from pituitary PRL mRNA but resembles the IM-9-P3 lymphoblast PRL transcript. Mol Cell Endocrinol 64:127-130

13. Bhatavdekar JM, Patel DD, Shah NG, Vora HH, Suthar TP, Ghosh N, Chikhlikar PR, Trivedi TI (2000) Prolactin as a local growth promoter in patients with breast cancer: GCRI experience. Eur J Surg Oncol 26:540-547

14. Clevenger CV, Chang WP, Ngo W, Pasha TL, Montone KT, Tomaszewski JE (1995) Expression of prolactin and prolactin receptor in human breast carcinoma. Evidence for an autocrine/ paracrine loop. Am J Pathol 146:695-705

15. Fields K, Kulig E, Lloyd RV (1993) Detection of prolactin messenger RNA in mammary and other normal and neoplastic tissues by polymerase chain reaction. Lab Invest 68:354-360

16. Ginsburg E, Vonderhaar BK (1995) Prolactin synthesis and secretion by human breast cancer cells. Cancer Res 55: 2591-2595

17. Reynolds C, Montone KT, Powell CM, Tomaszewski JE, Clevenger CV (1997) Expression of prolactin and its receptor in human breast carcinoma. Endocrinology 138:5555-5560

18. Shaw-Bruha CM, Pirrucello SJ, Shull JD (1997) Expression of the prolactin gene in normal and neoplastic human breast tissues and human mammary cell lines: promoter usage and alternative mRNA splicing. Breast Cancer Res Treat 44:243-253

19. Arendt LM, Evans LC, Rugowski DE, Garcia-Barchino MJ, Rui H, Schuler LA (2009) Ovarian hormones are not required for PRL-induced mammary tumorigenesis, but estrogen enhances neoplastic processes. J Endocrinol 203:99-110

20. Manhes C, Kayser C, Bertheau P, Kelder B, Kopchick JJ, Kelly PA, Touraine P, Goffin V (2006) Local over-expression of prolactin in differentiating mouse mammary gland induces functional defects and benign lesions, but no carcinoma. J Endocrinol 190:271-285

21. Gutzman JH, Miller KK, Schuler LA (2004) Endogenous human prolactin and not exogenous human prolactin induces estrogen receptor alpha and prolactin receptor expression and increases estrogen responsiveness in breast cancer cells. J Steroid Biochem Mol Biol 88:69-77

22. Liby K, Neltner B, Mohamet L, Menchen L, Ben-Jonathan N (2003) Prolactin overexpression by MDA-MB-435 human breast cancer cells accelerates tumor growth. Breast Cancer Res Treat 79:241-252

23. Svensson LA, Bondensgaard K, Norskov-Lauritsen L, Christensen L, Becker P, Andersen MD, Maltesen MJ, Rand KD, Breinholt J (2008) Crystal structure of a prolactin receptor antagonist bound to the extracellular domain of the prolactin receptor. J Biol Chem 283:19085-19094

24. Nielsen BS, Sehested M, Timshel S, Pyke C, Dano K (1996) Messenger RNA for urokinase plasminogen activator is expressed in myofibroblasts adjacent to cancer cells in human breast cancer. Lab Invest 74:168-177

25. Galsgaard ED, Rasmussen BB, Folkesson CG, Rasmussen LM, Berchtold MW, Christensen L, Panina S (2009) Re-evaluation of the prolactin receptor expression in human breast cancer. J Endocrinol 201:115-128
26. Clevenger CV, Ngo W, Sokol DL, Luger SM, Gewirtz AM (1995) Vav is necessary for prolactin-stimulated proliferation and is translocated into the nucleus of a T-cell line. J Biol Chem 270:13246-13253

27. Acosta JJ, Munoz RM, Gonzalez L, Subtil-Rodriguez A, Dominguez-Caceres MA, Garcia-Martinez JM, Calcabrini A, Lazaro-Trueba I, Martin-Perez J (2003) Src mediates prolactindependent proliferation of T47D and MCF7 cells via the activation of focal adhesion kinase/Erk1/2 and phosphatidylinositol 3-kinase pathways. Mol Endocrinol 17:2268-2282

28. McHale K, Tomaszewski JE, Puthiyaveettil R, Livolsi VA, Clevenger CV (2008) Altered expression of prolactin receptorassociated signaling proteins in human breast carcinoma. Mod Pathol 21:565-571

29. Wu WX, Brooks J, Millar MR, Ledger WL, Saunders PT, Glasier AF, McNeilly AS (1991) Localization of the sites of synthesis and action of prolactin by immunocytochemistry and in situ hybridization within the human utero-placental unit. J Mol Endocrinol 7:241-247

30. Llovera M, Pichard C, Bernichtein S, Jeay S, Touraine P, Kelly PA, Goffin V (2000) Human prolactin (hPRL) antagonists inhibit hPRL-activated signaling pathways involved in breast cancer cell proliferation. Oncogene 19:4695-4705

31. Howell SJ, Anderson E, Hunter T, Farnie G, Clarke RB (2008) Prolactin receptor antagonism reduces the clonogenic capacity of breast cancer cells and potentiates doxorubicin and paclitaxel cytotoxicity. Breast Cancer Res 10:R68

32. Peirce SK, Chen WY (2004) Human prolactin and its antagonist, hPRL-G129R, regulate bax and bcl-2 gene expression in human breast cancer cells and transgenic mice. Oncogene 23:1248-1255

33. Tan D, Walker AM (2010) Short form 1b human prolactin receptor down-regulates expression of the long form. J Mol Endocrinol 44:187-194

34. Plotnikov A, Varghese B, Tran TH, Liu C, Rui H, Fuchs SY (2009) Impaired turnover of prolactin receptor contributes to transformation of human breast cells. Cancer Res 69:3165-3172

35. Gadd SL, Clevenger CV (2006) Ligand-independent dimerization of the human prolactin receptor isoforms: functional implications. Mol Endocrinol 20:2734-2746

36. Xu J, Zhang Y, Berry PA, Jiang J, Lobie PE, Langenheim JF, Chen WY, Frank SJ (2011) Growth hormone signaling in human T47D breast cancer cells: potential role for a growth hormone receptor-prolactin receptor complex. Mol Endocrinol 25:597-610

37. Dikic I, Schlessinger J, Lax I (1994) PC12 cells overexpressing the insulin receptor undergo insulin-dependent neuronal differentiation. Curr Biol 4:702-708

38. Traverse S, Seedorf K, Paterson H, Marshall CJ, Cohen P, Ullrich A (1994) EGF triggers neuronal differentiation of PC12 cells that overexpress the EGF receptor. Curr Biol 4:694-701

39. Gutzman JH, Rugowski DE, Nikolai SE, Schuler LA (2007) Stat5 activation inhibits prolactin-induced AP-1 activity: distinct prolactin-initiated signals in tumorigenesis dependent on cell context. Oncogene 26:6341-6348

40. Xu XQ, Emerald BS, Goh EL, Kannan N, Miller LD, Gluckman PD, Liu ET, Lobie PE (2005) Gene expression profiling to identify oncogenic determinants of autocrine human growth hormone in human mammary carcinoma. J Biol Chem 280: 23987-24003

41. Ferraris J, Boutillon F, Bernadet M, Seilicovich A, Goffin V, Pisera D (2012) Prolactin receptor antagonism in mouse anterior pituitary: effects on cell turnover and prolactin receptor expression. Am J Physiol Endocrinol Metab 302:E356-E364 